\title{
Autologous Blood Product Donation
}

National Cancer Institute

\section{Source}

National Cancer Institute. Autologous Blood Product Donation. NCI Thesaurus. Code C133268.

Blood or blood product donations intended for transfusion at a later time to the donor. 